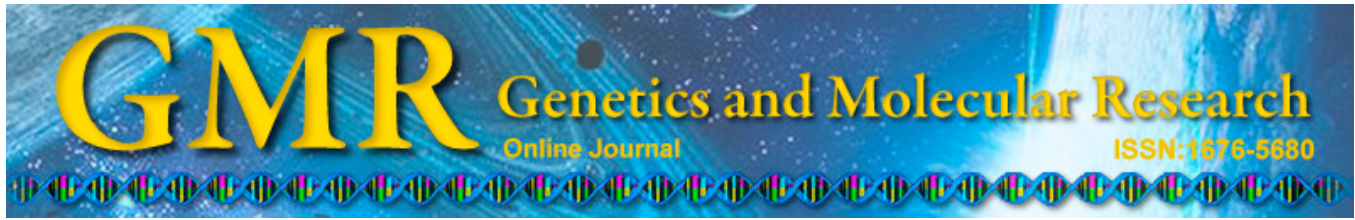

\title{
Isolation and characterization of polymorphic microsatellite loci for Pachycrepoideus vindemmiae (Rondani) (Hymenoptera: Pteromalidae)
}

\author{
W. Chen, L. Fang, J.L. Liu, Z. He and H.Y. Hu \\ Key Laboratory of Biotic Environment and Ecological Safety, \\ College of Life Sciences, Anhui Normal University, Wuhu, Anhui, China \\ Corresponding author: H.Y. Hu \\ E-mail: haoyuanhu@126.com \\ Genet. Mol. Res. 14 (1): 1798-1801 (2015) \\ Received February 26, 2014 \\ Accepted August 22, 2014 \\ Published March 13, 2015 \\ DOI http://dx.doi.org/10.4238/2015.March.13.7
}

\begin{abstract}
The parasitoid wasp Pachycrepoideus vindemmiae (Rondani) is a common pupal parasitoid of many fly pests that is distributed worldwide. This organism can be used for biological control in orchards or livestock farms. Identifying polymorphic microsatellite loci would be useful for analyzing the population genetic structure of the parasitoid. In the current study, based on a modified biotin-capture method, 10 polymorphic microsatellite loci were isolated and characterized for the insect, 7 of which did not deviate from Hardy-Weinberg equilibrium. The allelic number per locus varied from 3-7 $(\mathrm{N}=30)$. The expected and observed heterozygosities of 10 loci ranged from $0.369-0.775$ and from $0.300-0.867$, respectively.
\end{abstract}

Key words: Microsatellite markers; Pachycrepoideus vindemmiae; Polymorphism 


\section{INTRODUCTION}

Pachycrepoideus vindemmiae (Rondani) (Hymenoptera: Pteromalidae) is a cosmopolitan solitary ectoparasitoid that is $2-3 \mathrm{~mm}$ long and attacks the pupae of a range of cyclorrhaphous dipteran species, including Drosophila melanogaster, Ceratitis capitata, Rhagoletis sp, Delia radicum, Fannia canicularis, and Musca domestica (Rueda and Axtell, 1985), D. suzukii (Chabert et al., 2012), Cyrtoneurina pararescita (Postal, 2007), Megaselia scalaris (Marchiori and Barbaresco, 2007), and Sarcodexia lambens (Marchiori et al., 2003). This parasitoid had been used to biologically control such fly pests as house and stable flies (Petersen et al., 1992). It is also effective against spotted-wing Drosophila, D. suzukii, a new invasive species that harms berry orchards in the United States and Europe (Chabert et al., 2012).

Simple sequence repeats (SSRs) or microsatellite DNA, are powerful molecular markers that can be used to study intra- or inter-specific variation and the genetic structure of biological populations. Previous studies have analyzed the sex ratio of parasitoids using molecular markers (Abe et al., 2009; Sahand et al., 2012). No SSR markers have been reported for this insect.

\section{MATERIAL AND METHODS}

Samples of $P$. vindemmiae were collected from the campus of Anhui Normal University, Wuhu, Anhui Province, China, and were maintained with the pupae of the house fly $M$. domestica. Parasitoid wasps and houseflies were reared in a climatic chamber with a light: dark photoperiod $(14: 10 \mathrm{~h})$. Temperature and relative humidity were $25 \pm 1{ }^{\circ} \mathrm{C}$ and $60 \pm 5 \%$, respectively (Hu et al., 2012). Genomic DNA was extracted from ethanol-preserved samples using a standard proteinase K/phenol extraction protocol (Sambrook and Russell, 2001).

The method was based on a modified biotin-capture method (Hamilton et al., 1999). Following Sau3AI (TaKaRa, Shiga, Japan) digestion of genomic DNA, fragments of 400-1000 bp were removed and purified using an Agarose Gel Purification Kit (Axygen, Union City, CA, USA). The purified fragments were then ligated to 2 adaptor oligonucleotides (adaptor A: 5'-GGCCAGAGACCCCAAGCTTCG; adaptor B: 5'-PO4-GATCCGAAGCTTGGGGTCTCTGGCC) using a DNA Ligation Kit (TaKaRa). The DNA was hybridized using biotinylated oligonucleotides $(\mathrm{AC})_{12},(\mathrm{AG})_{12}$, and (ACAT) ${ }_{6}$ probes (Sangon, Shanghai, China). These heteroduplexes were then selected using Streptavidin Magnetic Particles (Promega, Madison, WI, USA) and the DNA was enriched by polymerase chain reaction using the adaptor $\mathrm{A}$ as the forward and reverse primers. Microsatellite-enriched DNA fragments were ligated into the PMD-18T vector (TaKaRa), transformed to DH5 $\alpha$ cells and plated onto Luria-Bertani agar medium with ampicillin. A total of 350 positive clones were selected and sequenced on ABI PRISM 3730 automated sequencer (Applied Biosystems, Foster City, CA, USA). Next, 120 primer pairs were designed based on nucleotide sequence regions flanking microsatellites using the Primer 5 software. Only 12 sets of primers showing consistent and specific polymerase chain reaction products were used for further polymorphism analysis and the others were rejected because they lacked an amplification product or because of nonspecific amplification. Polymorphisms in microsatellite loci were analyzed using TP-M13-SSR according to the method of Zhu et al. (2011) and microsatellite loci were shown to be polymorphic. 
Tests of significant deviation from Hardy-Weinberg equilibrium (HWE) and linkage disequilibrium were performed using GENEPOP version 3.4 (Raymond and Rousset, 1995). Micro-Checker version 2.2.3 (van Oosterhout et al., 2004) was used to test for the presence of null alleles. The CERVUS 2.0 program (Marshall et al., 1998) was used to determine the allele frequencies and observed and expected heterozygosities (Nei, 1987).

\section{RESULTS AND DISCUSSION}

The numbers of alleles, size ranges, and observed and expected heterozygosities are shown in Table 1. The number of alleles per locus varied from 3-7 and expected and observed heterozygosities ranged from $0.369-0.775$ and from $0.300-0.867$, respectively. No significant linkage disequilibrium among pairwise comparisons of microsatellite loci was detected. Three loci (BL2, BL5, and BL7) were found to significantly deviated from HWE $(\mathrm{P}<0.01)$. The reasons that account for deviation from HWE may be population bottleneck effects or inbreeding. Because the samples were cultured in a laboratory, inbreeding rather population effects may account for the 3 deviations from HWE detected in the current study. Although the polymorphisms were low because of inbreeding, the microsatellite loci isolated in this study will be useful for investigating the genetic diversity and future analyses of the $P$. vindemmiae population.

\begin{tabular}{|c|c|c|c|c|c|c|c|}
\hline Locus & Primer sequences $\left(5^{\prime}-3^{\prime}\right)$ & Repeat motif & $\mathrm{Ta}\left({ }^{\circ} \mathrm{C}\right)$ & $\begin{array}{l}\text { Size range } \\
\text { alleles (bp) }\end{array}$ & No. of alleles & $H_{\mathrm{o}}$ & $H_{\mathrm{E}}$ \\
\hline BL1 & $\begin{array}{l}\text { F: GCAGACACCCACACATACAT } \\
\text { R: GGAGGCGAAATTTGTTGCT }\end{array}$ & $(\mathrm{TC})_{12}$ & 55.5 & $162-174$ & 6 & 0.700 & 0.745 \\
\hline BL2 & $\begin{array}{l}\text { F: CGTCCATTGGAGAGACATCG } \\
\text { R: TGTATATCGCGCACGGACC }\end{array}$ & $(\mathrm{CT})_{11}$ & 55.7 & 156-169 & 7 & 0.867 & 0.695 \\
\hline BL3 & $\begin{array}{l}\text { F: AGCCATCGTGATTTCTCCG } \\
\text { R: CGATACACGCGCGTCTATTC }\end{array}$ & $(\mathrm{TC})_{13}$ & 55.4 & 166-182 & 5 & 0.567 & 0.684 \\
\hline BL4 & $\begin{array}{l}\text { F: AGCGAGCAAAGGTAGTGGTG } \\
\text { R: CACCGACCATCGTCATTATCT }\end{array}$ & $(\mathrm{AG})_{10} \mathrm{TA}(\mathrm{AG})_{7}$ & 51.7 & $211-215$ & 3 & 0.300 & 0.369 \\
\hline BL5 & $\begin{array}{l}\text { F: CGACGTAAAAAGTCATTACGAGTC } \\
\text { R: ATTTCCAATTTGGCACGGTC }\end{array}$ & $(\mathrm{AG})_{8}$ & 52.9 & $130-149$ & 5 & 0.567 & 0.711 \\
\hline BL6 & $\begin{array}{l}\text { F: GCATCGTCTCCTGAACAATC } \\
\text { R: GATACCACTCGCACGAGGT }\end{array}$ & $(\mathrm{AG})_{11}$ & 51.8 & $128-174$ & 7 & 0.633 & 0.754 \\
\hline BL7 & $\begin{array}{l}\text { F: GCGAAGGTGAAACGGAGAA } \\
\text { R: ATAGGCATACGTGCGACAGC }\end{array}$ & $(\mathrm{AG})_{9}$ & 53.7 & $157-167$ & 7 & 0.600 & 0.775 \\
\hline BL8 & $\begin{array}{l}\text { F: CGTTTCTGTTTGTCATCGACAG } \\
\text { R: AGATGGTTCGGCGATAAAGA }\end{array}$ & $(\mathrm{AG})_{10}$ & 53.0 & $155-177$ & 5 & 0.500 & 0.547 \\
\hline BL9 & $\begin{array}{l}\text { F: TCAGCATTAAATGGCGTCG } \\
\text { R: CACTTGAGCGCGTTCAATC }\end{array}$ & $(\mathrm{GA})_{11}$ & 54.4 & $172-184$ & 6 & 0.600 & 0.728 \\
\hline BL10 & $\begin{array}{l}\text { F: GTCTGCCTCGTCTCGGATT } \\
\text { R: AGCGAGCGAGTGAGAGAGTAAG }\end{array}$ & $(\mathrm{GA})_{11}$ & 55.7 & 282-292 & 4 & 0.600 & 0.648 \\
\hline
\end{tabular}

Ta is the annealing temperature; $H_{\mathrm{O}}$ and $H_{\mathrm{E}}$ are the observed and expected heterozygosities, respectively.

\section{ACKNOWLEDGMENTS}

Research supported by the National Natural Science Foundation of China (\#31172145), the Specialized Research Fund for the Doctoral Program of Higher Education of China (\#20113424120005), the Natural Science Foundation of Anhui Province (\#1408085MKL24), and the Fund from Provincial Key Laboratory of Conservation and Utilization for Important Biological Resource in Anhui. 


\section{REFERENCES}

Abe J, Kamimura Y, Shimada M and West SA (2009). Extremely female-biased primary sex ratio and precisely constant male production in a parasitoid wasp Melittobia. Anim. Behav. 78: 515-523.

Chabert SR, Allemand M, Eslin P and Gibert P (2012). Ability of European parasitoids (Hymenoptera) to control a new invasive Asiatic pest, Drosophila suzukii. Biol. Control 63: 40-47.

Hamilton MB, Pincus EL, Di Fiore A and Fleischer RC (1999). Universal linker and ligation procedures for construction of genomic DNA libraries enriched for microsatellites. Biotechniques 27: 500-502, 504-507.

Hu HY, Chen, ZZ, Duan BS, Zheng JT, et al. (2012). Effects of female diet and age on offspring sex ratio of the solitary parasitoid Pachycrepoideus vindemmiae (Rondani) (Hymenoptera, Pteromalidae). Rev. Bras. Entomol. 56: 259-262.

Marchiori CH and Barbaresco LF (2007). Occurrence of Pachycrepoideus vindemmiae (Rondani, 1875) (Hymenoptera: Pteromalidae) as a parasitoid of Megaselia scalaris (Loew, 1866) (Diptera: Phoridae) in Brazil. Braz. J. Biol. 67: 577-578.

Marchiori CH, Pereira LA and Silva Filho OM (2003). Primeiro relato do parasitóide Pachycrepoideus vindemmiae (Rondani) (Hymenoptera: Pteromalidae) parasitando pupas de Sarcodexia lambens Wiedemann (Diptera: Sarcophagidae). Cien. Rur. 33: 173-175.

Marshall T, Slate J, Kruuk L and Pemberton J (1998). Statistical confidence for likelihood-based paternity inference in natural populations. Mol. Ecol. 7: 639-655.

Nei M (1987). Molecular Evolutionary Genetics. Columbia University Press, New York.

Petersen JJ, Watson DW and Pawson BM (1992). Evaluation of Muscidifurax zaraptor and Pachycrepoideus vindemmiae (Hymenoptera: Pteromalidae) for controlling flies associated with confined beef cattle. Biol. Control 24: 44-50.

Postal C (2007). New host for the parasitoid Pachycrepoideus vindemmiae (Rondani) (Hymenoptera: Pteromalidae) in Brazil. Arq. Bras. Med. 59: 271-272.

Raymond M and Rousset F (1995). Genepop (version 3.4): population genetics software for exact tests and ecumenicism. J. Hered. 86: 248-249.

Rueda L and Axtell R (1985). Comparison of Hymenopterous parasites of house fly, Musca domestica (Diptera: Muscidae), pupae in different livestock and poultry production systems. Environ. Entomol. 14: 217-222.

Sahand K, Sean M and Ian C (2012). Primary and secondary sex ratios in a gregarious parasitoid with local mate competition. Behav. Ecol. 2: 435-443.

Sambrook J and Russell D (2001). Molecular Cloning a Laboratory Manual. 3rd edn. Cold Spring Harbor Laboratory, Cold Spring Harbor.

van Oosterhout C, Hutchinson W, Wills D and Shipley P (2004). Micro-Checker: software for identifying and correcting genotyping errors in microsatellite data. Mol. Ecol. Notes 4: 535-538.

Zhu YF, Hu J, Han R, Wang Y, et al. (2011). Finger printing and identification of closely related wheat (Triticum aestivum L.) cultivars using ISSR and fluorescence-labeled TP-M13-SSR marker. Aust. J. Crop Sci. 5: 846-850. 